\title{
Análise do processo de expansão dos loteamentos e suas implicações no espaço urbano do município de Barbalha-Ceará-Brasil
}

\author{
Analysis of expansion process of plot and its implications in space urban county Barbalha - \\ Ceará - Brazil
}

\author{
Silva $^{1}$, F. M.A.; Bandeira $^{2}$, A. P.; Ribeiro ${ }^{3}$, S. C.; Brito ${ }^{4}$, D. S. \\ Email:mcgeoalencar@gmail.com
}

\begin{abstract}
Resumo
O objetivo principal desta pesquisa consiste na realização de uma análise sobre a instalação e expansão de loteamentos residências e suas principais implicações no espaço urbano municipal de Barbalha - CE. Metodologicamente foi realizado o levantamento bibliográfico e cartográfico, essas informações foram trabalhadas a fim da integração dos dados, onde foi utilizado o Software Arcgis e Qgis para o tratamento cartográfico e análise dos dados obtidos na secretaria de infraestrutura de Barbalha. O município de Barbalha destaca-se dentro da RM Cariri pela importância econômica, educacional e médico-hospitalar, influenciando nos processos de supervalorização da terra que pode ser percebida pela quantidade de loteamentos criados nos últimos 10 anos, no qual atraiu diferentes classes sociais da RMC, concentrando-se principalmente na divisa municipal entre Juazeiro do Norte e Barbalha. Alguns loteamentos estão situados na planície de inundação da bacia hidrográfica do Rio Salamanca ou em relevos dissecados implicando principalmente em processos de instabilidade natural ou inundação que são agravados pela atividade Humana nessas áreas. Sugere-se a importância da elaboração da carta geotécnica como orientação para os municípios tomarem medidas para ocupar adequadamente seus terrenos e determinando áreas onde os parcelamentos urbanos não devem ser realizados.
\end{abstract}

\begin{abstract}
The objective of this research is to realization out an analysis of the installation and expansion of residentials developments and their implications in the urban space of city of Barbalha - CE. Methodologically was realized survey bibliographic and cartographic, this information was worked to the integration of data, which was used Arcgis and Qgis softwares for cartographic processing and analysis of data obtained in Barbalha in infrastructure secretariat. The city of Barbalha stands out within the RM Cariri by economic importance, educational and healthcare, influencing the overvaluation process of land that can be perceived by the amount of allotment created in the last 10 years, which attracted different social classes of RMC, focusing mainly on the border between of city Juazeiro and in city Barbalha. Some allotment are situated in the flood plain of the river hydrographic basin Salamanca or on dissected reliefs, resulting mainly in natural instability processes or flood are aggravated by Human activity in these areas. It suggests the importance of preparation of geotechnical letter as a guide for municipalities to take steps to properly take their land and determining areas where urban subdivisions should not be performed.
\end{abstract}

Keywords: Allotments.Urbanization.Barbalha.

Palavras-chave: Loteamentos.Urbanização.Barbalha.

\section{INTRODUÇÃO}

O povoamento do Cariri cearense iniciou-se com os índios Kariris que entre os séculos XVII e XVIII foram exterminados por colonizadores baianos e sergipanos e tiveram suas terras tomadas e doadas a colonos criadores de gado por ordem do governador, na época, de Pernambuco, a partir daí o processo de ocupação foi intensificado. Inicialmente o uso foi principalmente para criação bovina;

\footnotetext{
${ }^{1}$ Francisco Marciano de Alencar Silva, PRODER, Uiversidade Federal do Cariri-UFCA, Juazeiro do Norte-CE,Brasil

${ }^{2}$ Ana Patrícia Nunes Bandeira, CCT, Universidade Federal do Cariri - UFCA, Juazeiro do Norte-CE, Brasil

${ }^{3}$ Simone Cardoso Ribeiro, DEGEO, Universidade Regional do Cariri-URCA, Crato-CE, Brasil

${ }^{4}$ Denise da Silva Brito, CCT, Universidade Estadual do Ceará - UECE, Fortaleza, CE, Brasil
} 
posteriormente, visto a fertilidade do solo e recurso hídrico constante, propícios ao plantio, assim como pelas divergências e incompatibilidade de uso entre agricultores e criadores, as terras da região foram tomadas pela agricultura (PINHEIRO, 2009).

Durante os anos recorrentes, a produção de milho, feijão, frutas regionais, farinha de mandioca, além do algodão, favoreceu o crescimento econômico local. No entanto, a atividade de destaque foi o plantio da cana-de-açúcar, que entre o século XVIII e XIX consolidou Barbalha como pólo canavieiro e grande produtor de rapadura. Contava com mais de 70 engenhos, 13 fábricas de aguardente e 150 casas de farinha, sendo considerada uma das cidades mais ricas da região. O aproveitamento das condições naturais da planície do rio Salamanca favoreceu uma rica produção de derivados da cana para o município de Barbalha. Foi através do Cariri que começou a indústria açucareira para o estado do Ceará, promovendo, inclusive, um processo migratório direcionado para a região em foco (PINHEIRO, 2009).

Além das condições naturais, que funcionava como atrativo de pessoas para a região, as questões políticas e sociais também dinamizavam a sua paisagem. A emancipação da cidade de Barbalha em 1876 trouxe vários empreendimentos como o Gabinete de Leitura (1889), o jornal Correio do Cariri, vários colégios, a Liga Barbalhense contra o Analfabetismo, além das ordens religiosas que se implantaram na cidade, como a dos padres Salvatorianos e das freiras Beneditinas na década de 1950. Estes últimos foram fundamentais para a evolução do município, pois fomentou a educação e ajudaram a fixar as primeiras unidades de saúde do município como o Hospital São Vicente de Paula, existente até os dias atuais (ARAÚJO, 2013). Ainda assim, mesmo com o crescimento do espaço urbano, as práticas agrícolas ainda eram de extrema importância econômica ao dinamismo urbano contemporâneo.

A dinâmica industrial do município de Barbalha teve seu ápice e declínio na década de 1960 e 1970. No entanto, nesta mesma época houve o declínio do cultivo da cana-de-açúcar, o que mudou a dinâmica espacial do uso da terra no município. Foi a partir da segunda metade do século XX que Barbalha passou por um processo de industrialização, buscando alternativas para a crise na economia canavieira. Surgem assim as fábricas de cimento - IBACIP, de ladrilhos cerâmicos CECASA, a usina de açúcar e a fábrica de soro fisiológico. Também na década de 1970 foi criado o Balneário do Caldas, visando aproveitar o potencial turístico das fontes minerais e da beleza da Chapada do Araripe. Hoje, além desse, outros balneários utilizam o potencial hídrico das fontes para construir uma paisagem de lazer, levando o consumo de um ambiente que se volte para a natureza (LIMA, 2014). Este, dentre outros empreendimentos impulsionou o crescimento urbano como o aumento de loteamentos nas proximidades do centro urbano com ênfase principalmente na divisa municipal com juazeiro do Norte. 
Neste trabalho o estudo da expansão dos loteamentos tem um caráter importante, pois tem como recorte espacial o município de Barbalha que compõe junto com Juazeiro do Norte e Crato o triângulo denominado CRAJUBAR. Com as tradições festivas e culturais de Barbalha e Crato, acoplados com o rápido crescimento econômico (industrial, comercial e de serviços) de Juazeiro do Norte, configura-se um espaço dinâmico econômico e socialmente. Esso fato chamou a atenção do capital público e privado, os quais enxergaram como um lugar atrativo e de futuro promissor dentro de seus interesses. Diante destas condições está acontecendo um rápido crescimento urbano não só em Crato e Juazeiro do Norte, mais também em Barbalha (PEREIRA et al, 2010).

Desta forma, o objetivo principal desta pesquisa consiste na realização de uma análise sobre a instalação e expansão de loteamentos residências e suas principais implicações no espaço urbano municipal de Barbalha- CE.

\section{1 Área de estudo}

O município de Barbalha localiza-se na latitude de $7^{\circ} 18^{\prime} \mathrm{S}$ e longitude $38^{\circ} 55^{\prime}$, possui altitude média de 415,74 m e está na Região Metropolitana do Cariri, Mesorregião Sul Cearense (Figura 1). Apresenta uma área de 451,9 $\mathrm{km}^{2}$, ou seja, aproximadamente 0,34\% do Estado do Ceará. Limita-se com os municípios de Juazeiro do Norte e Crato (norte), Jardim e o estado do Pernambuco (sul), Missão Velha (leste) e Crato (oeste).

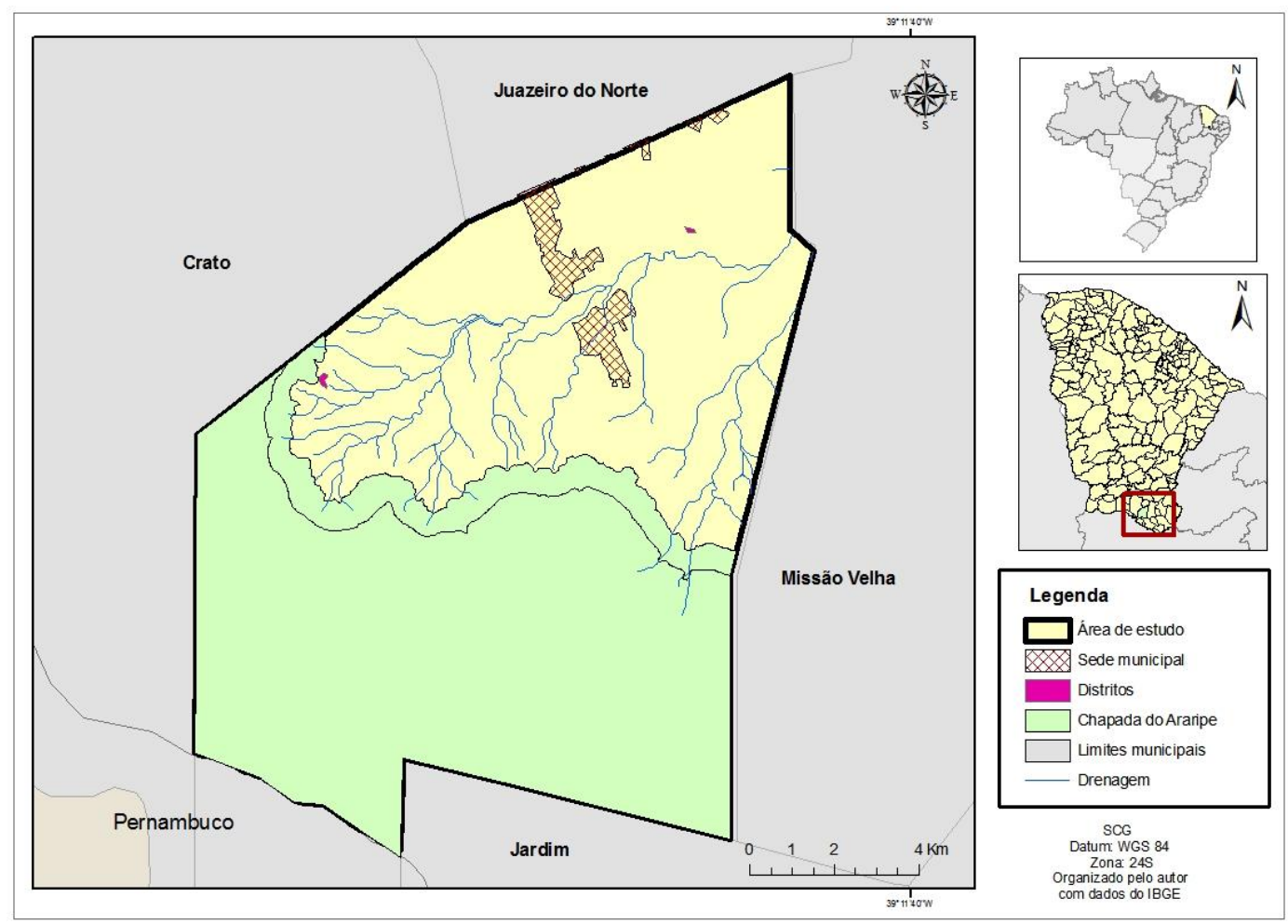

Figura 1: Localização da área de estudo. Fonte: Organizado com dados do IBGE (2010). 


\section{METODOLOGIA}

Este trabalho foi realizado a partir de um levantamento bibliográfico e cartográfico. O mapa de localização foi elaborado a partir de bases cartográficas disponibilizadas pelo Instituto Brasileiro de Geografia e Estatística-IBGE (2010) com escala de 1:100.000. O mapa de distribuição de loteamentos foi elaborado a partir de bases cartográficas disponibilizada pela Fundação Cearense de Meteorologia e Recursos Hídricos - FUNCEME (2012) e IBGE (2010) sendo que os lotes e as rodovias foram vetorizados utilizando a ferramenta Open Layers Plugin a partir de imagens do Google satélite (2015) no SIG QGIS 2.14.

Em ambiente computacional, foi utilizado o Sistema de Informações Geográficas - SIG (ARCGIS) onde os mapas/cartas pré-existentes foram trabalhados em camadas (layers) de acordo com o tipo de informações, tanto de elementos vetoriais como matriciais convertidos para arquivo do SIG ARCGIS 9.3.

A distribuição de loteamentos criados entre 2005 a 2016 foi organizada a partir de dados disponibilizados pela Secretaria de Infraestrutura do município de Barbalha. Os dados foram tabelados por loteamentos, localização, área total em $\mathrm{m}^{2}$ e ano de criação de cada loteamento.

\section{RESULTADOS E DISCUSSÃO}

A formação dos primeiros loteamentos urbanos no município iniciou-se ainda na segunda metade do século XX. Sob influência da implantação industrial, Barbalha sofre significativas mudanças no crescimento urbano na década de 60 quando a Cerâmica do Cariri S/A, implantada as margens da CE-293, impulsionou a formação do bairro Buriti, os conjuntos habitacionais Malvinas, Vila Santa Teresinha e Vila São José. Em 1982, nas proximidades da indústria de cimento Portland o governo municipal implanta o loteamento privado Bela Vista, no eixo Sul de expansão da cidade (ARAÚJO, 2013).

De 2005 a 2016, segundo dados informados pela prefeitura municipal de Barbalha, foram criados 15 loteamentos de variadas dimensões, situados em diversos pontos do município, sendo que 08 deles estão nas proximidades da divisa com Juazeiro do Norte, contribuindo para o processo de conurbação urbana (Figura 2). Os mais valorizados encontram-se neste conjunto próximo a divisa com Juazeiro do Norte, dentre estes se podem destacar os loteamentos: Royalville, Lagoa Seca III, Barbalha Village II e III. Segundo Araujo (2013), esses empreendimentos, atraiu a classe 
mais abastarda da região que estabeleceram suas mansões e negócios ligados ao entretenimento e serviços. A Tabela 1 está elencada alguns loteamentos do município onde é possível observar o ano de criação, sua localização e a dimensão.

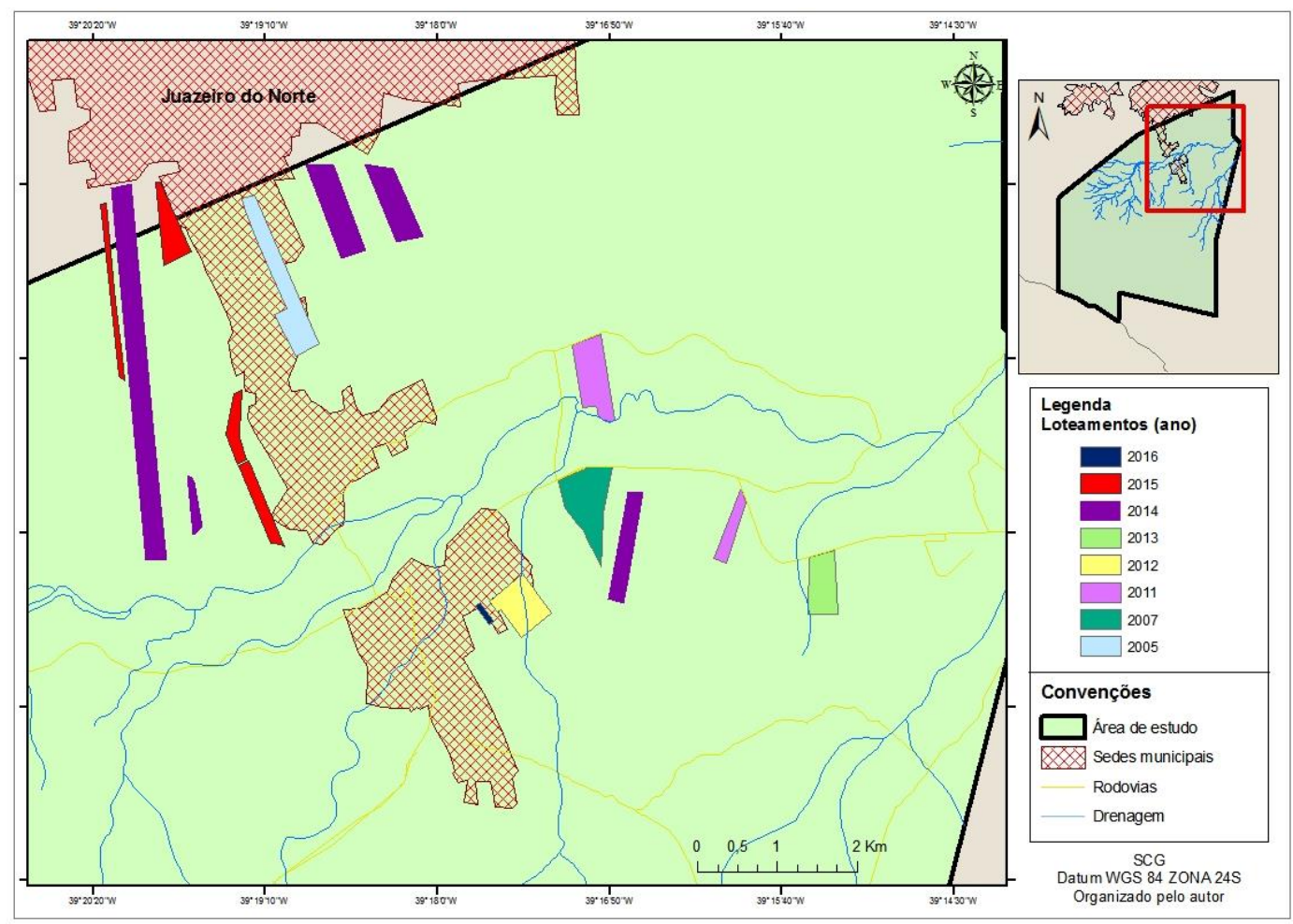

Figura 2: distribuição espacial de loteamentos no município de Barbalha-Ce (2005 a 2016). Fonte: Organizado com dados da FUNCEME (2012) e IBGE (2010). Os lotes e as rodovias foram vetorizados a partir de imagens do Google Earth, 2015.

Tabela 1 - Distribuição de loteamentos no Município de Barbalha/ CE - (2009- 2016). Fonte: Organizado pelo autor com dados disponibilizados pela secretaria municipal de infra-estrutura de Barbalha/CE (2016).

\begin{tabular}{c|c|c|c}
\hline LOTEAMENTO & LOCALIDADE & $\begin{array}{c}\text { ÁREA } \\
\text { TOTAL }\left(\mathbf{m}^{\mathbf{2}}\right)\end{array}$ & ANO \\
\hline Valle Verde & Alto da Alegria & $198 \mathrm{~m}^{\mathbf{2}}$ & 2016 \\
\hline Arte residence & Sítio Mata dos Limas & $244.704,23$ & 2015 \\
\hline Barbalha Village II & Sítio Bulandeira & $325.345,31$ & 2015 \\
\hline Park do sol & Sítio Lambedor & $2011.893,85$ & 2015 \\
\hline Lagoa Seca III & Sítio Lagoa & $830.512,16$ & 2015 \\
\hline Barbalha Village III & Sítio Bulandeira & $171.929,39$ & 2014 \\
\hline Delta Park & Sítio Lagoinha & $583.835,49$ & 2014 \\
\hline Jeserva Cariri & Distrito Estrela & $93.569,99$ & 2014 \\
\hline Sardim Buriti & Sítio Lambedor & $792.245,00$ & 2014 \\
\hline Jardins dos Ipês & Aítio cabeção do brejo & $282.229,09$ & 2013 \\
\hline
\end{tabular}




\begin{tabular}{c|c|c|c}
\hline Jardim Nova Barbalha & Sítio Buriti & $104.042,41$ & 2011 \\
\hline Residencial do Valle & Sítio São Paulo & $7.577,26$ & 2011 \\
\hline Morada cysne & Sítio Buriti & $445.723,21$ & 2007 \\
\hline Royalville & Malvinas & $132.274,70$ & 2005 \\
\hline
\end{tabular}

Sobre a ocupação de unidades geomorfológicas é importante ressaltar as diferenças de ocupação. Enquanto algumas vezes as formas de relevo são condicionantes para a forma de ocupação, em outras situações as ações políticas fogem dessa condição. Neste sentido, as colinas que antes limitavam a expansão urbana, são ocupadas com a desapropriação de terras e distribuição de loteamentos para a população. É assim que surgiu em 1969, por exemplo, o bairro Alto da Alegria, contrariando a tendência natural de expansão do eixo sul da malha urbana de Barbalha (ARAÚJO, 2013). Um exemplo de loteamento recente que foi projetado em uma área de declividade alta é o Valle verde, recentemente construído em 2016, tornando a área suscetível a processos erosivos devido a atividades humanas associadas à exploração do solo.

Desta forma, a ocupações em morros ou colinas para implantação de loteamentos podem intensificar os processos geomorfológicos de encostas, acarretando na retirada da proteção natural do solo, a vegetação e, consequentemente, na evolução de processos erosivos. Atualmente é comum a ocorrência desses processos próximos às moradias da área de estudo, deixando a população sob algum tipo de risco associado à instabilidade do solo. Além do aumento do potencial erosivo do solo, o sedimento erodido das encostas se deposita nas áreas de baixada, intensificando o risco de inundações na planície.

No setor leste do município encontra-se um conjunto de 06 loteamentos, além do Morada Cysne, outro loteamento que chama atenção neste conjunto é o Residencial do Valle, construído em 2011 na planície do rio Salamanca nas proximidades do leito do rio. Segundo Brito (2016) esta área é bastante suscetível a enchentes e alagamentos durante eventos intensos de precipitação. No tocante aos solos, na planície encontra-se os Neossolos Flúvicos classificado por Pinheiro et al (2015) como solos frágeis com alta suscetibilidade à erosão devido ser um solo de textura arenosa.

Diante da constatação do crescimento do município de Barbalha e da Região do Cariri, é interessante a elaboração de instrumentos que auxiliam o planejamento urbano das cidades. Quando o crescimento de um município se dá sem planejamento é muito provável o surgimento de diversos problemas ambientais e a geração de áreas de riscos. Dentre os instrumentos recomendados para auxiliar o planejamento urbano destaca-se a Carta Geotécnica de Aptidão à Urbanização, que é produzida através do zoneamento e classificação acerca de sua aptidão frente aos desastres naturais 
(alagamentos, erosão, deslizamentos e outros), possibilitando uma indicação quanto aos potenciais riscos de sua ocupação futura (ver BANDEIRA et. al., 2016).

\section{CONSIDERAÇÕES FINAIS}

Conforme os resultados apresentados pode-se concluir que o crescimento dos loteamentos iniciou-se ainda na metade do século XX, após a queda no cultivo da cana de açúcar. Como alternativa para suprir a crise, Barbalha passa por um processo industrialização que acarretou a construção dos primeiro loteamentos urbanos nas proximidades dessas indústrias.

O processo de ocupação dos loteamentos mais recentes ocorreu e vem ocorrendo, devido o crescimento econômico e consequentemente populacional da região. Este fator contribuiu para a super valorização da terra em diversos pontos do município com ênfase principalmente para a divisa municipal com Juazeiro do Norte, favorecendo o fenômeno conurbação entres os dois municípios. Junto a esses fatores ocorrem também as implicações desses loteamentos no espaço como, por exemplo, ocupação em áreas suscetíveis a processos naturais de erosão, enchentes e inundações que associados a atividades humanas e sua ocupação intensificam mais ainda estes processos, surgindo áreas de ricos no município.

A prevenção de novas situações de risco pode estar associada a processos de urbanização que venham a ser instalados em áreas vazias, ainda não parceladas, e em áreas já parceladas que ainda se encontram com urbanização incompleta. Neste sentido sugere-se ao município de Barbalha a construção da Carta Geotécnica de Aptidão Urbanística frente aos Desastres Naturais, a fim de obter informações que orientem o parcelamento do solo no processo de uso e ocupação, de forma equilibrada com a condição de suporte do meio físico, evitando-se os riscos e as consequências dos desastres e proporcionando uma ocupação adequada do solo urbano.

\section{REFERÊNCIAS}

ARAÚJO, R. S. Análise histórica do processo de expansão urbana das cidades de Barbalha, Crato e Juazeiro do Norte. (Dissertação de Mestrado), apresentado ao Programa de PósGraduação em Desenvolvimento Regional Sustentável, UFC - Campus Cariri, 2013. p.185.

BANDEIRA, A. P. N.; SILVA, C. A. U. ; VERISSIMO, C. U. V.; TAVARES, P. R. L.; LUNA, R. M. Relatório Final: Carta Geotécnica de Aptidão À Urbanização Frente aos Desastres Naturais do Município de Caucaia-CE. Relatório enviado ao Ministério das Cidades, sendo produto final do Termo de Cooperação firmado com a Universidade Federal do Cariri. 2016. 
BRITO, D. S. Risco de inundação em enclaves úmidos no semiárido: o caso da bacia do rio Salamanca, Barbalha/Ceará. (Dissertação de Mestrado) apresentado ao Programa de PósGraduação em Geografia, UECE - Fortaleza: 2016. p.186.

DINIZ, N. C. Automação da Cartografia Geotécnica: Uma Ferramenta de Estudos e Projetos para Avaliação Ambiental. Tese (Doutorado). Escola Politécnica da Universidade de São Paulo SP. 1998.

FUNCEME (Fundação Cearense de Meteorologia e Recursos Hídricos). Levantamento de reconhecimento de média intensidade de solos: mesorregião do sul cearense. Fortaleza, 2012. $280 \mathrm{p}$.

IBGE (Instituto Brasileiro de Geografia e Estatística) Bases e Referências cartográficas, 2010. Disponível em: http://mapas.ibge.gov.br/bases-e-referenciais/bases-cartograficas.html. Acesso em: março de 2016.

LIMA, G. G. Análise Comparativa de Metodologias de Mapeamento Geomorfológico na Bacia do Rio Salamanca, Cariri Cearense. (Dissertação de Mestrado) apresentado ao programa de Pós Graduação em Geografia da Universidade Federal do Pernambuco-UFPE, Recife, 2014. p.120

PEREIRA, C. S. S.; OLIVEIRA, J. C. A.; Cidade e Reestruturação do espaço: a Região Metropolitana do Cariri (RMC) e a nova dinâmica no Estado do Ceará. In: I Seminário das Metrópoles - Cidades e Práticas Espaciais: diferentes dinâmicas em metrópoles brasileiras nacionais e regionais. Goiânia, 2010. p. 01-12. Disponível em: http://docslide.com.br/documents/cidade-ereestruturacao-do-espaco-a-regiao-metropolitana-do-cariri-e-a-nova-dinamica-urbana-no-estado-doceara-claudio-smalley.html. Acesso em: junho de 2016.

PINHEIRO, I. O Cariri: seu descobrimento, povoamento, costumes. Fortaleza, CE: Fundação Waldemar Alcântara, 2009. 296 p.

PINHEIRO, M. A.; BRITO, D. S.; SILVA, J.M.O . Vulnerabilidade Ambiental à Erosão de Solos na Microbacia do Rio Salamanca em Barbalha-Ceará, Brasil. In: XXXV Congresso Brasileiro de Ciência do Solo, Natal-RN, 2015 v. Unico. Disponível em: http://www.cbcs2015.com.br/anais/index.php. Acesso em: junho de 2016.

SÁ, M. Y. C. F. Os homens que faziam o tupinambá moer: experiência e trabalho em engenhos de rapadura no Cariri (1945-1980). (Dissertação de Mestrado) apresentado ao Programa de PósGraduação em História Social/ UFC, 2007. p.362. 


\section{AGRADECIMENTOS}

Sinceros agradecimentos a FUNCAP- Fundação Cearense de Apoio ao Desenvolvimento Científico e Tecnológico, pelo financiamento das pesquisas assim como ao Programa de PósGraduação em Desenvolvimento Regional Sustentável da Universidade Federal do Cariri- UFCA e também a prefeitura municipal de Barbalha pelas informações prestadas.

Recebido em: 14/08/2016

Aceito para publicação em: 01/10/2016 